mingt reolining on s temporary bed, in the same position The in when the so-called romiting occurred. On the foor was a large pool of blood, apparently mired with matter. There was a considerable swelling in front, and to the right side of the trachea, which fluctuated freely, and occupied the whole of the inferior division of the anterior triangle of the neck. It had been coming about a woek, commencing with hest and tenderness, and some constitutional disturbance. Since the discharge, the swelling had diminished in size; the breathing, which all day had been difficult, was now somewhat relieved. The child, directly after the loss of blood, had been very faint, but had by this time rallied. There was a constant expectoration of thick matter, tinged with blood. There was evidently a considerable abscess, which had opened into the trachea, and laid open an artery, or a considerable branch, as well. I ordered the child to be kept very quiet, to take nothing warm, and that I should be summoned immediately if any more urgent symptoms should come on.

Passing the house a few hours after, I called. The child seemed easy; no difficulty of breathing; no more hæmorrhage than what I before mentioned as tinging the expectorated matter, and the swelling appeared diminishing. I hoped for the best; but the child died suddenly early the next morning. Having fallen asleep, and being awoke by a sense of suffocation, he had coughed up a great quantity of blood, and died, before the mother could summon aid. I made a post mortem examination of the part two days after. On turning back the skin and cervical fascia, a great quantity of coagulated blood was discovered; this being cleared away, the cavity of the abscess was found to extend to the right side of, and behind the upper part of the trachea and the os hyoides, opening into the former at the back, opposite the third or fourth ring. The hæmorrhage proceeded from a branch of the superior thyroid artery.

I do not think I should have been justified, however unfortunate the termination of this case was, in attempting any operative measure; the uncertainty as to the source of the hæmorrhage was so great. It might have been from the superior or inferior thyroid arteries of either side, or from the carotid of the right side: and it would have been a hazardous proceeding to have laid open the cavity of the abscess, now filled with coagulum, and searched for the bleeding vessels, the patient already much exhausted by the preceding hxmorrhage. Besides which, the child's state seemed to farour the hope that she might yet do well; the swelling had diminished, and so had the difficulty of breathing, whilst the hæmorrhage at the time of my two visits was very slight indeed.

\section{CASE OF COMA WITH PNEUMONIA IN A CHILD.}

By H. PAYNE, M.D., Barnsley.

Or the 20th October last, I was called at 11 o'clock P.M. to the infant daughter of Mr. G. Ward, of this town, aged $1 \frac{1}{2}$ year, to give my opinion as to the nature of the disease under which it was suffering; Dr. Jackson, who was in attendance, having a different opinion from one expressed by a surgeon who had seen the child on the same day, during his absence. I found the child speechless, and in a state bordering on profound coma; the pupils being dilated, insensible to light, and fixed; eyelids closed. Slight cough. Expiration attended with a little grunting effort and noise, indicative of pulmonary disease. Respiratory murmur faint, and nearly absent. Pustules on chest, from use of ung. antim. Face flushed. Pulse 120, strong. Bowels and urinary bladder free. Had never had a fit nor seizure before. In the absence of vomiting, strabismus, and scrofulous symptoms, I directly diagnosed a state of coma, arising from venous congestion caused by pneumonia. As the child could swallow, isinglass and milk were given. The port wine which it was taking to bo omitted. Appli- cotur stupe sinspis part. inferiori corporis per sextam part. hore.

Habeat mist. scillø cum sp. æth. nitr. Cap. pulv, antim. gr. ss nocte maneque ad iv vices.

Oct. 21st. Was sensible to the sinapism. Stupor continues. Expectoration copious. Restless when coughing. Contin. mist.

App. sinapis. nuchæ. Habeat ol. ricini coch. parv.

Oct. 23rd. The lethargic states continues. Cough troublesome. Applic. sinap. carpis.

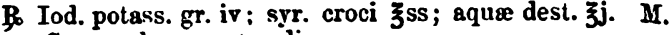
Cap. coch. parv. ter die.

Rep. pulv. antim. iv.

Oct. 24th. Expectoration stiii frec. ज̈̈üpo: the soms, but pupils contracted and insensible. Takes little support, preferring cold milk.

Oct. 25th. Stupor much less. The child now cries when coughing. Pupils sensitive. There is considerable colic, which a few teaspoonfuls of rue tea, and the addition of tinct. card. co. to the iodine mixture, removed.

Oct. 26th. The stupor has passed off, leaving a feeble fretful state. Coughs little. Takes solid food, and can sit up. To have a teaspoonful occasionally of wine whey.

The iodine mixture was continued up to the lst instant, when, a few boils appearing, it was discontinued. It was given as a stimulant.

Nov. 12th. The father of the child informs me that it is recovering, though slowly; and has several times been out of doors.

Nor. 15th. It is now well.

RExarks. There are three diseases with which this comatose condition in children may be confounded; viz., hydrocephalus, inflammation of the brain. and remittent fever. A careful scrutiny will suffice to distinguish the above symptoms of venous congestion from those of ramollissement, excited arterial action, or serous effusion. In the above case, the respiration afforded the surest guide to a pneumonic affection, which the parents, indeed, could trace to the child having taken cold.

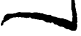

\section{CASE OF PUERPERAL CONVULSIONS.}

By H. J. WATERLAND, Esq., Kirton Lindsey.

On the 18th of July last, about 5 P.M., I was called to Mrs. R., aged 28 years, primipara, who was then in labour. I found that pains had commenced early that morning, and were proceeding steadily, and that the os uteri was partially dilated; all the signs were then favourable ones. The patient, for the latter months of preguancy, had been much harassed by nausea and romiting, with confined bowels; so that scarcely a day had passed without her rejecting the contents of the stomach. From a strong aversion to medicine, she had taken no aperients of any kind: recently she often drank two or three glasses of porter daily, finding no article of drink or food agree with her so well. She had also completely neglected outdoor exercise. There had been spontaneous diarrhoea that morning and the day before. Her temperament seemed lymphatic; her conformation was short and stout; her complexion very clear and fair, but pale; her sensitiveness to pain appeared very acute; the pulse habitually rather weak.

The labour seemed to progress in every respect farourably, until about half-past eleven, or a quarter to midnight; the head of the child then beginning to press upon the perinæum. At this juncture, suddenly, without warning, convulsions, beginning in the muscles of the face and neck and gradually inrolving those of the rest of the body, occurred to a degree that the patient could hardly be kept in bed. These violent muscular contractions subsided in about five minutes, and were followed by insensibility with some degree of stertor. About this time the child was brought into the world. It was smali in size, and did not inspire till the warm bath and artificial inflation were employed. The placents was expelled soon after the child; 
the uterus did not contract vell, as considerable hrmorrhage occurred immediately after. The pulse, while the patient remained unconscious after the convulsions, was plow and just perceptible, gradually regaining volume and strength in about twenty or twenty-fire minutes after; but, probsbly owing to the hwmorrhage, remained weak. Consciousness appeared to be returning, when a secend attack of convulsions, of the same kind as the last, but longer in passing off, occurred, followed by the same comatose state as before. This time consciousness never returned up to the next attack of conpulsions. As hæmorrhage had been going on prett5 freely all this time, the uterus alternately contracting and dilating, and expelling a quantity of blood each time, I judged that depletion had gone far enough, and endeavoured by pressure, cold, etc., to produce permanent uterine contraction. This was not an easy matter, however, during the convulsions, which soon re. curred, as she tossed about violently; but ultimately, I succeeded by pressure of the hand in causing a pretty firm contraction, though there was still a slight discharge of blood.

About 3, or between 3 and 4 A.M., Mr. C., for whom a messenger had been dispatched at the first occurrence of the convulsions, arrived. He seemed to think that hæmorrhage had gone quite far enough; and as there was still a slight discharge from the uterus, and this viscus was rather large; he passed his hand into it, and extracted some clots, after which the pressure of a bandage caused it to contract firmly. There had been previously cold applied to the head, and a sinapism between the shoulders.

Mrs. R. now had sinapisms applied to the head and calves of the legs. The convulsions after this several times recurred up to 8 P.M., when the patient lay unconscious; skin cold and clammy, pupils dilated and insensible, breathing stertorous, pulse as nearly as possible imperceptible, power of swallowing suspended. She remained in this state for some time, but then gradually reaction crept on, warmth became slowly restored to the surface, and the power of swallowing returned. Advantage was taken of this to administer a stimulating draught, composed of some spirit of ammonia and spirit of lavender, which Mr. C. happened to have with him. This had the effect of making her vomit the medicine itself, and with it some partly digested fish, which it seemed she had eaten the previous day. Reaction now proceeded slowly; but it was afternoon before she could answer questions collectedly, and had entirely regained consciousness. There was no returu of the convulsions; and she convalesced without any unfavourable symptoms, save irritation of the lower extremities, and considerable oedema of the face and head, apparently owing to the sinapisms, which had been left on for too long a time. It was some weeks before she had regained strength sufficiently to sit up.

The friends of the patient having been privately informed by some member of the profession, who, no doubt, was influenced by the most benevolent motives, that the case was wrongly treated, inasmuch as venesection should have been performed, and was not-I refrain from any remarks, and content myself with stating the facts as they occurred, of which the profession in general must judge.

\section{CASE OF EXTRA-UTERINE PREGNANCY.}

By PYE H. CHAVASSE, F.li.C.S., late President of Queen's College Medico-Chirur, ical Society, Birmingham.

[Read before the Socicti in the Spring of 1⒌5.]

LasT year I had a case of cxtra-uterine pregnancy; and as it contains many points of interest, I have much pleasure in bringing it before your notice. Before making any further remarks on the subject, I will, if you please, give the history of the case, which I have copied almost verbatim from my note-book.

On January lst, 1852, I was sent for to Mrs. H. She is 39 jears of age; has had several children, but has only one child living. Sometime in the beginning of August 1851, (1) while passing the Malding, and, by accident, struck her a violent blow of the building, and, by accident, struck her a violont be was on the abdomen with a basket of potatoes, which he was carrying. She immediately fainted, and, on recovering from the syncope, she complained of great pain of the part which had been struck, and felt very ill. Soon after, she was seized with a violent peritonitis. The medical mnn in attendance treated her very actively; he ordered, at difierattendance treated leches to the abdomen, and salivated her. Under this treatment, the symptoms of peritonitis ceased; but still the patient continued very ill.

The first medical man (a physician) gave up the case to general practitioner, who was puzzled, as he well might and could not make out the nature of the complaint.

Her sufferings at this time, both day and night, were most horrible, and withoutany intermission. In proof of which, me declared that, in one day, she took six powerful composing draughts, and without deriving any relief. She had posing draughts, and without deriving any rell number; but instead of getting better, she became rapidly worse. Her sufferings had so reduced her, that she was more like a skeleton than a living woman.

On January lst, 1852, I saw her for the first time. On careful examination, I found a large. tumour midway between the superior fortion of the hypogastric and the inferior portion of the umbilical region, rather inclining to the right iliac, and assuming somewhat the shape of a the right iliac, and assuming somewhat the shape could gravid uterus; it was hard and immovable, and cotalion in not detect fluctuation, or, or that time, the umbilicus, had given way for several inches in extent, and had allowed a given way for several the bowels. This ventral hernia was large protrusion of the bowels. This vas (and it was frequently) excessively painful whe The bels were completely loaded with fæcal matter. She was not able to make water without pressing firmly over the region of the bladder. She had not menstruated since the accident in August. Some months before I was called in, she had had a very copious and long continued purulent discharge, but which had entirely ceased upon my arrival.

The examination, per vaginam, threw but little light on the case. There was a large substance of some kind nearly blocking up the pelvis, but of what nature, I could not decide. The vagina was pushed out of its proper course, instead of being "oblique from below upwards and backwards, and its axis corresponding with that of the outlet of the pelvis", the posterior wall of the ragina was pushed forwards, the anterior wall was drawn directly upwards behind the pubes, and narrowed like a funnel. The os uteri was too high up to be felt; otherwise, probably, it would be found looking towards the upper part of the os pubis.

The impression upon my mind, on first seeing the case, was, that she had an ovarian tumour, attended with engorged fæcal state of the bowels. Indeed, the bowels were so loaded, that they were as hard as a board, and the peristaltic action, in consequence, could scarcely be performed. My first duty, therefore, was to thorouginly clear out the bowels. This I did, and with the happiest effect. She became a new woman; her appetite, her strength, her sleep, her spirits, all returned, and she quite made up her mind that she should recover.

After I had been in attendance upon her for six weeks or two months, that is to say, towards the end of February (and five months after the accident) strong symptoms of pregnancy showed themselves; her breasts enlarged; there was a dark areola around the nipple; milk in quantities (containing milk globules) could be squeezed out of them; the tumour of the abdomen gradually increased in size, and extended more anteriorly, and motion was felt in it. The stethoscope, too, now decidedly told of a fotal circulation. With these decisive symptoms, all doubts of its being anything but pregnancy vanished; especially, as the tumour came more in front, and assumed more the shape of a gravid uterus. 